\title{
Produção de fitomassa e acúmulo de nutrientes por plantas de cobertura e cultivo da mamona em sucessão no sistema plantio direto
}

\author{
Cover crops phytomass and nutrient accumulation and castor bean grown in succession under \\ no-tillage system
}

\author{
André Godoy da Silva ${ }^{\mathrm{I}}$ Carlos Alexandre Costa Crusciol $^{\mathrm{I}}$ Rogério Peres Soratto ${ }^{\mathrm{I*}}$ \\ Claudio Hideo Martins da Costa ${ }^{\mathrm{I}}$ Jayme Ferrari Neto $^{\mathrm{I}}$
}

\section{RESUMO}

\begin{abstract}
Objetivou-se avaliar a produção de matéria seca (MS) e o acúmulo de nutrientes pela crotalária (Crotalaria juncea L.) e pelo milheto (Pennisetum glaucum (L.) R. Brown), em cultivos isolado e consorciado, e o efeito do manejo mecânico da palhada no desempenho da cultura da mamona (Ricinus communis L.), em sucessão, na fase de implantação do sistema plantio direto. O experimento foi instalado em um Nitossolo Vermelho (Rhodic Kandiudox), em Botucatu, São Paulo (SP) (22 $58^{\prime} S, 48^{\circ} 23^{\prime} W$ e $765 m$ de altitude). O delineamento utilizado foi o de blocos casualizados, em parcelas subdivididas, com quatro repetições. As parcelas foram constituídas por três coberturas vegetais: crotalária - cultivar 'IAC-KR1'; milheto - cultivar 'BN 2'; e consórcio crotalária + milheto. As subparcelas foram constituídas pela ausência e presença do manejo mecânico da palhada com triturador horizontal 20 dias após o manejo químico. $O$ milheto produziu maior quantidade de MS e apresentou maiores teores de $\mathrm{K}, \mathrm{Mg}$ e $S$ na parte aérea, enquanto a crotalária apresentou maiores teores de $\mathrm{N}$ e Ca. O milheto acumulou mais $N, P, K, M g$ e $S$ na parte aérea, enquanto a crotalária acumulou maior quantidade de Ca. A produtividade de grãos da mamoneira foi maior em sucessão ao consórcio crotálaria + milheto e na ausência do manejo mecânico da palhada.
\end{abstract}

Palavras-chave: Ricinus communis, Pennisetum glaucum, Crotalaria juncea, manejo mecânico.

\section{ABSTRACT}

The objective of this study was to evaluate aboveground matter production and nutrients accumulation by sunnhemp (Crotalaria juncea L.) and pearl millet (Pennisetum glaucum (L.) R. Brown), in sole crop and intercropped, and the effect of straw mulch mechanical management on castor bean (Ricinus communis L.) performance,

\begin{abstract}
in notillage system establishment. The experiment was carried out on a Rhodic Kandiudox, in Botucatu, SP, Brazil (22 $58^{\circ}$ 'S, $48^{\circ} 23^{\prime} \mathrm{W}$ and $765 \mathrm{~m}$ above sea level). A randomized block design, in a splitplot scheme, with four replications, was used. The plots were composed by three cover crops: sunnhemp - $c v$. 'IAC-KRI'; pearl millet - cv. 'BN 2'; and intercropping sunnhemp + pearl millet. The subplots were composed by absence or presence of straw mulch mechanical management, by horizontal crusher use, 20 days after chemical management. Pearl millet sole crop produced greater dry matter and showed higher $K, M g$, and $S$ concentration in aboveground, 75 days after emergence, while $N$ and Ca concentration were higher in sunnhemp. Pearl millet sole crop accumulated greater amounts of $N, P, K, M g$, and $S$, in aboveground, while sunnhemp accumulated elevated amount of Ca. Castor bean grain yield was higher in succession to sunnhemp + pearl millet intercropping and in the absence of straw mulch mechanical management.
\end{abstract}

Key words: Ricinus communis, Pennisetum glaucum, Crotalaria juncea, mechanical management.

\section{INTRODUÇÃO}

O óleo contido nas sementes da mamona (Ricinus communis L.) é matéria-prima de aplicações únicas na indústria química (SANTOS et al., 2007), sendo também opção para a produção de biocombustível (NASS et al., 2007; ZUCHI et al., 2010). Assim, tem sido desenvolvidos novos híbridos e cultivares de porte baixo adaptados aos sistemas de produção mecanizados e em larga escala. Esses materiais podem ser inseridos nos sistemas de rotação/

'Departamento de Produção Vegetal (Agricultura), Faculdade de Ciências Agronômicas (FCA), Universidade Estadual Paulista (UNESP), Campus de Botucatu, CP 237, 18610-307, Botucatu, SP, Brasil. E-mail: soratto@fca.unesp.br. *Autor para correspondência. 
sucessão de culturas, em sistema plantio direto (SPD), tornando-se importante alternativa para produtores de grãos.

No SPD, é notória a necessidade de rotação de espécies com elevada capacidade de produção de biomassa de qualidade (OLIVEIRA et al., 2002), principalmente, em regiões de inverno seco, onde a produção e manutenção da palhada são mais difíceis. Assim, o emprego de gramíneas tropicais, notadamente o milheto (Pennisetum glaucum (L.) R. Brown), pode ser uma alternativa para produção de palhada em grande quantidade e com características de maior persistência sobre o solo, viabilizando e sustentando o SPD nessas regiões. Além disso, de acordo com CRUSCIOL \& SORATTO (2009), o milheto é uma espécie de alta capacidade de extração de nutrientes do solo, com amplas vantagens de reciclagem, principalmente de $\mathrm{N}$ e K, reduzindo os riscos de lixiviação. Especificamente quanto ao $\mathrm{N}$, as leguminosas, entre elas a crotalária (Crotalaria juncea L.), adicionam esse nutriente pela fixação biológica do $\mathrm{N}$ atmosférico, contribuindo para o aumento da disponibilidade de $\mathrm{N}$, além de ciclar outros nutrientes para culturas em sucessão (PERIN et al., 2004).

O cultivo consorciado de plantas de cobertura gramíneas com leguminosas pode ser uma alternativa viável para o sistema de rotação quanto ao fornecimento de maior quantidade e qualidade de fitomassa (PERIN et al., 2004; 2006). O consórcio crotalária mais milheto, além de fornecer palhada com maior persistência (CAZZETA et al., 2005), incrementa principalmente os teores de $\mathrm{K}$ e $\mathrm{N}$ no solo para as culturas em sucessão (PERIN et al., 2004), notadamente o primeiro e o segundo nutriente mais extraídos pela mamona, respectivamente (NASCIMENTO, 2010).

Os efeitos positivos dos resíduos da plantas tendem a aumentar com o tempo que eles permanecem na superfície do solo. Esse tempo depende do tipo de resíduo, da quantidade, da composição química, especialmente da relação $\mathrm{C} / \mathrm{N}$, do grau de contato com o solo e do grau de trituração (ROSOLEM et al., 2004). Assim, este é o tipo de manejo da palhada que pode influenciar a decomposição e, consequentemente, a liberação de nutrientes para a cultura em sucessão (ARGENTA et al., 2001). Porém, o uso de implementos específicos para o manejo da palhada, como o triturador de palha horizontal, pode acarretar desvantagens, como baixo rendimento operacional, alto custo e risco de compactação do solo (DENARDIN \& KOCHHANN, 1993). Contudo, pouco se sabe sobre o efeito da planta de cobertura e do manejo da palhada sobre o desempenho da cultura da mamoneira em sucessão.

O objetivo do trabalho foi avaliar a produção de MS e o acúmulo de nutrientes pela crotalária e pelo milheto, em cultivos isolado e consorciado, e o efeito do manejo mecânico da palhada no desempenho da cultura da mamona em sucessão, na fase de implantação do SPD.

\section{MATERIAL E MÉTODOS}

Conduziu-se o experimento na Fazenda Experimental Lageado da Faculdade de Ciências Agronômicas (UNESP), Botucatu, São Paulo (SP) ( $22^{\circ} 58^{\prime} \mathrm{S}, 48^{\circ} 23^{\prime} \mathrm{W}$ e $765 \mathrm{~m}$ de altitude). O solo do local é um Nitossolo Vermelho (Rhodic Kandiudox) e até cerca de seis meses antes da instalação do experimento cultivou-se cana-de-açúcar na área. No inverno de 2004, cultivou-se aveia-preta na área. Segundo a classificação climática de Köeppen, o clima predominante na região é do tipo Cwa. É caracterizado pelo clima tropical de altitude, com inverno seco e verão quente e chuvoso. Os totais mensais de precipitação pluvial registrados na área experimental, durante os meses de novembro de 2004 a junho de 2005 , foram na sequência de 95, 160, 430, 70, 120, 88, 130 e 60mm.

Determinaram-se as características químicas do solo $(0-20 \mathrm{~cm})$ antes da instalação do experimento, e os resultados foram: $25,0 \mathrm{~g} \mathrm{dm}^{-3}$ de M.O.; $\mathrm{pH}\left(\mathrm{CaCl}_{2}\right)$ 5,$0 ; 17,0 \mathrm{mg} \mathrm{dm}^{-3} \mathrm{deP}$ (resina); 1,6, 33,3, 17,6 e 34,1mmol $\mathrm{dm}^{-3}$ de $\mathrm{K}, \mathrm{Ca}, \mathrm{Mg}$ e $\mathrm{H}+\mathrm{Al}$, respectivamente; e $61 \%$ de saturação por bases.

Adotou-se o delineamento experimental de blocos casualizados, em esquema de parcelas subdivididas, com quatro repetições. As parcelas foram constituídas por três coberturas vegetais: crotalária C. juncea cultivar 'IAC-KR1', milheto - P. glaucum cultivar 'BN-2' e consórcio crotalária + milheto. As subparcelas foram constituídas pela ausência ou presença do manejo mecânico da palhada, mediante uso de triturador de palha horizontal, 20 dias após manejo químico. Cada subparcela apresentava $5 \mathrm{~m}$ de largura por 15 metros de comprimento, perfazendo uma área total de $75 \mathrm{~m}^{2}$.

Antes da semeadura das espécies de cobertura realizou-se a dessecação das plantas presentes na área com a utilização do herbicida glyphosate (1.920 $\mathrm{g} \mathrm{ha}^{-1}$ i.a.). As espécies de cobertura foram semeadas, sem adubação, em 21/10/2004, no espaçamento de $0,17 \mathrm{~m}$ entrelinhas e aproximadamente $0,05 \mathrm{~m}$ de profundidade, sendo utilizados $40,20 \mathrm{e}$ $20+10 \mathrm{~kg} \mathrm{ha}^{-1}$ de sementes de crotalária, milheto e crotalária + milheto, respectivamente. A emergência das plantas ocorreu no dia 30/10/2004.

Aos 75 dias após a emergência (DAE) das culturas de cobertura, realizou-se a coleta das plantas de cobertura (14/01/2005), para determinação da 
produção de MS e do teor de nutrientes. Foram amostrados dois quadros, com $0,25 \mathrm{~m}^{2}$ de área interna (amostras simples), que constituíram uma amostra composta. Os resíduos sofreram pré-limpeza por meio de peneiras, para remoção do solo aderido, em seguida foram lavados sem o emprego de detergente, agitandoos por alguns segundos em água deionizada, em três porções sucessivas, sendo depois colocados sobre papel absorvente. O material foi seco em estufa com circulação forçada de ar, a $60^{\circ} \mathrm{C}$, e pesado, para a determinação da produtividade de MS. Posteriormente, realizou-se a determinação dos teores de macronutrientes (N, P, K, Ca, Mg e S), segundo MALAVOLTA et al. (1997), e carbono, pelo método de Walkley \& Black, descrito por TEDESCO et al. (1985). De posse dos resultados, calcularam-se a relação $\mathrm{C} / \mathrm{N}$ e as quantidades de nutrientes acumuladas por hectare.

Após as coletas, foi realizada a dessecação das plantas com aplicação de glifosate $\left(1.920 \mathrm{~g} \mathrm{ha}^{-1} \mathrm{do}\right.$ i.a.). Realizou-se a semeadura da mamona no dia 17/02/ 2005, utilizando-se o híbrido Íris, no espaçamento 0,45m entrelinhas e na densidade de 45.000 plantas ha $^{-1}$. A adubação mineral de semeadura constou da aplicação de $250 \mathrm{~kg} \mathrm{ha}^{-1}$ da fórmula N-P-K 08-28-16. A emergência da cultura ocorreu no dia 23/02/2005. Durante a condução da cultura, não se realizou adubação de cobertura e não houve a necessidade de realização de tratos culturais, como a aplicação de defensivos agrícolas.

Por ocasião da colheita da mamona (05/07/ 2005), determinaram-se os componentes da produção (população final de plantas, número de racemos por planta, número de frutos por racemo, número médio de grãos por fruto e massa de cem grãos) e a produtividade de grãos (13\% de umidade).

Os dados obtidos foram submetidos à análise de variância, e as médias foram comparadas por meio do teste de $\mathrm{t}$ (DMS), a 5\% de probabilidade. As análises estatísticas foram realizadas utilizando o programa computacional SISVAR, versão 4.3 (FERREIRA, 2000).

\section{RESULTADOS E DISCUSSÃO}

A produção de MS variou entre as coberturas vegetais (Tabela 1). O milheto se destacou, com produção média de $14.040 \mathrm{~kg} \mathrm{ha}^{-1}$ de MS. CRUSCIOL \& SORATTO (2009) verificaram produção de MS do milheto bastante semelhante. Contudo, CAZETTA et al. (2005), semeando o milheto no mês de setembro e com manejo aos 60DAE, CRUSCIOL \& SORATTO (2007), com semeadura em novembro e manejo aos 71DAE, e SOUZA et al. (2008), com semeadura em fevereiro e manejo aos 59DAE, observaram produções inferiores, ou seja, 10.673, 8.909 e $6.100 \mathrm{~kg} \mathrm{ha}^{-1}$, respectivamente.

A crotalária $\left(8.111 \mathrm{~kg} \mathrm{ha}^{-1}\right)$ e o consórcio $\left(8.470 \mathrm{~kg} \mathrm{ha}^{-1}\right)$ não diferiram entre si quanto à produção de MS, com resultados próximos aos observados por MENEZES et al. (2009), estudando as mesmas espécies, com produções de MS de $8.689 \mathrm{~kg} \mathrm{ha}^{-1}$, para a crotalária, e $9.183 \mathrm{~kg} \mathrm{ha}^{-1}$, para consórcio crotalária + milheto, entretanto por um período de crescimento mais longo (90DAE) do que no presente trabalho (75DAE). Já CAZETTA et al. (2005), com semeadura em setembro e manejo aos 60DAE, observaram menor produção de MS da crotalária, com $5.267 \mathrm{~kg} \mathrm{ha}^{-1}$. NASCIMENTO \& SILVA (2004) verificaram produção de MS da crotalária muito inferior do que no presente estudo. Para as espécies de cobertura e o consórcio, as produções de MS foram superiores a $6.000 \mathrm{~kg} \mathrm{ha}^{-1}$, considerada por DAROLT (1998) como a quantidade mínima ideal de adição de MS em um sistema de rotação de culturas, para que se mantenha cobertura adequada do solo.

Tabela 1 - Matéria seca (MS), relação C/N, teores e quantidades acumuladas de macronutrientes na parte aérea das plantas de cobertura. Médias de oito repetições.

\begin{tabular}{|c|c|c|c|c|c|c|c|c|}
\hline \multirow{2}{*}{ Tratamento } & \multirow{2}{*}{ MS $\left(\mathrm{kg} \mathrm{ha}^{-1}\right)$} & \multirow{2}{*}{ Relação C/N } & $\mathrm{N}$ & $\mathrm{P}$ & $\mathrm{K}$ & $\mathrm{Ca}$ & $\mathrm{Mg}$ & S \\
\hline & & & \multicolumn{6}{|c|}{ - } \\
\hline Crotalária & $8.111 \mathrm{~b}$ & $35,4 \mathrm{~b}$ & $22,9 \mathrm{a}$ & $2,3 \mathrm{a}$ & $13,0 \mathrm{c}$ & $8,9 \mathrm{a}$ & $2,4 b$ & $1,7 \mathrm{~b}$ \\
\hline Milheto & $14.040 \mathrm{a}$ & $42,4 \mathrm{a}$ & $18,3 b$ & $2,7 \mathrm{a}$ & $22,9 \mathrm{a}$ & $4,0 \mathrm{c}$ & $3,4 \mathrm{a}$ & $2,5 \mathrm{a}$ \\
\hline Crotalária+Milheto & $8.470 \mathrm{~b}$ & $42,1 \mathrm{a}$ & $19,0 \mathrm{~b}$ & $2,5 \mathrm{a}$ & $16,0 \mathrm{~b}$ & $5,4 \mathrm{~b}$ & $2,6 b$ & $1,9 b$ \\
\hline \multirow[t]{2}{*}{$\mathrm{CV}(\%)$} & 11,1 & 8,1 & 9,4 & 14,7 & 7,1 & 5,3 & 7,6 & 8,1 \\
\hline & & & & - & antidade & ulada $(\mathrm{kg}$ & ----- & ------- \\
\hline Crotalária & - & - & $184,4 \mathrm{~b}$ & $18,7 \mathrm{~b}$ & $107,3 b$ & $71,1 \mathrm{a}$ & $19,7 \mathrm{~b}$ & $13,8 b$ \\
\hline Milheto & - & - & $257,3 a$ & $38,5 \mathrm{a}$ & $321,5 \mathrm{a}$ & $56,6 \mathrm{ab}$ & $47,4 \mathrm{a}$ & $35,0 \mathrm{a}$ \\
\hline Crotalária+Milheto & - & - & $161,0 \mathrm{~b}$ & $21,6 b$ & $136,1 b$ & $45,8 b$ & $22,3 b$ & $16,5 b$ \\
\hline $\mathrm{CV}(\%)$ & - & - & 11,7 & 22,3 & 13,3 & 17,5 & 12,0 & 15,2 \\
\hline
\end{tabular}

Médias seguidas por letras iguais, na coluna, não diferem entre si pelo teste t(DMS), a 5\% de probabilidade.

Ciência Rural, v.40, n.10, out, 2010. 
Segundo ALVARENGA et al. (2001), a quantidade de palha sobre o solo e a uniformidade de sua distribuição podem servir de referência para uma avaliação preliminar sobre as condições em que o SPD está se desenvolvendo. A alta produção de MS das espécies utilizadas como planta de cobertura esteve relacionada com a época de cultivo, já que não ocorreram restrições hídricas durante o ciclo destas.

A relação $\mathrm{C} / \mathrm{N}$ do milheto e do consórcio crotalária + milheto foi superior à da crotalária (Tabela 1). PERIN et al. (2006), estudando a produção de MS de diferentes espécies de cobertura, observaram maior relação C/N para o milheto (30) em comparação com a crotalária (13). Esses resultados também foram observados neste trabalho, entretanto com valores superiores (milheto $=42$ e crotalária $=35$ ) aos observados na literatura.

A crotalária apresentou maior teor de $\mathrm{Ne} \mathrm{Ca}$ na parte aérea que o milheto e o consórcio (Tabela 1). A crotalária tem grande potencial para fixar biologicamente o N atmosférico (PERIN et al., 2004). Os teores de P foram semelhantes em todas as coberturas vegetais. $\mathrm{O}$ milheto apresentou maiores teores de $\mathrm{K}, \mathrm{Mg}$ e S que a crotalária e o consórcio (Tabela 1). CRUSCIOL \& SORATTO (2007) verificaram, em milheto semeado em novembro e manejado 71DAE, teores de $\mathrm{Ca}\left(5,2 \mathrm{~g} \mathrm{~kg}^{-1}\right)$ e $\mathrm{S}\left(3,6 \mathrm{~g} \mathrm{~kg}^{-1}\right)$ maiores, de $\mathrm{N}\left(13,3 \mathrm{~g} \mathrm{~kg}^{-1}\right), \mathrm{P}\left(1,5 \mathrm{~g} \mathrm{~kg}^{-1}\right) \mathrm{e}$ $\mathrm{K}\left(13,9 \mathrm{~g} \mathrm{~kg}^{-1}\right)$ menores e de $\mathrm{Mg}\left(3,2 \mathrm{~g} \mathrm{~kg}^{-1}\right)$ semelhantes aos valores observados no presente trabalho. Segundo CARPIM et al. (2008), o maior acúmulo de nutrientes no milheto ocorre no início do florescimento (52 dias após semeadura). Já para a crotalária, o maior teor de $\mathrm{N}$ nas folhas é observado aos 60 dias após a semeadura (MENDONÇA\& SCHIAVINATO, 2005).
Para a quantidade acumulada de nutrientes, verificou-se, com exceção ao $\mathrm{Ca}$, que o milheto foi superior à crotalária e ao consórcio de ambas (Tabela 1). Assim, mesmo não tendo apresentado maior teor de $\mathrm{N}$, o milheto apresentou maior acúmulo desse nutriente em razão da maior produção de MS por área. CRUSCIOL \& SORATTO (2009) verificaram que os acúmulos de N, $\mathrm{P}, \mathrm{K}, \mathrm{Ca}, \mathrm{Mg}$ e S pelo milheto foram de 206, 20, 215, 74, 44 e $116 \mathrm{~kg} \mathrm{ha}^{-1}$, respectivamente, para uma produção de MS de $14.800 \mathrm{~kg} \mathrm{ha}^{-1}$. Já BOER et al. (2007) observaram acúmulos de 122, 17, 40 e 18kg ha-1 de N, P, $\mathrm{Mg}$ e $\mathrm{S}$ pelo milheto, respectivamente, para uma produção de MS de $10.801 \mathrm{~kg} \mathrm{ha}^{-1}$, valores inferiores ao observados neste trabalho. Por outro lado, os mesmos autores verificaram acúmulo de $\mathrm{K}\left(417 \mathrm{~kg} \mathrm{ha}^{-1}\right) \mathrm{eCa}(76 \mathrm{~kg}$ ha $^{-1}$ ) superiores aos observados no presente trabalho. CAZZETA et al. (2005) verificaram valores de $\mathrm{Ca}$ acumulado díspares ao observados no presente trabalho, inferiores na crotalária $\left(45 \mathrm{~kg} \mathrm{ha}^{-1}\right)$ e crotalária + milheto $\left(41 \mathrm{~kg} \mathrm{ha}^{-1}\right)$ e superior no milheto $\left(63 \mathrm{~kg} \mathrm{ha}^{-1}\right)$, para quantidades de MS de 5.267, 8.455 e $10.673 \mathrm{~kg} \mathrm{ha}^{-1}$, respectivamente. Segundo CRUSCIOL \& SORATTO (2007), essa variação pode estar relacionada à fertilidade do solo, à adubação utilizada, ao estádio fenológico em que foi realizada a avaliação e à parte da planta avaliada.

Quanto à cultura da mamona, não houve efeitos significativos da interação planta de cobertura $\mathrm{x}$ manejo da cobertura vegetal sobre nenhuma das características agronômicas. As populações finais de plantas foram maiores nos tratamentos com milheto solteiro e consorciado com a crotalária (Tabela 2). A ausência de manejo mecânico das coberturas com triturador de palha também proporcionou maior população final de plantas. Isso pode ter ocorrido

Tabela 2 - População final de plantas, número de racemos por planta, número de frutos por racemo, número de grãos por fruto, massa de 100 grãos e produtividade de grãos da cultura da mamona, cultivada no sistema plantio direto sobre palhada de diferentes plantas de cobertura, com e sem manejo mecânico da palhada.

\begin{tabular}{lcccccc}
\hline Tratamentos & $\begin{array}{c}\text { População final } \\
\left(\text { pl. ha }{ }^{-1}\right)\end{array}$ & $\begin{array}{c}\mathrm{N}^{\mathrm{o}} \text { de racemos } \\
\text { por planta }\end{array}$ & $\begin{array}{c}\mathrm{N}^{\mathrm{o}} \text { de frutos } \\
\text { por racemo }\end{array}$ & $\begin{array}{c}\mathrm{N}^{\mathrm{o}} \text { de grão } \\
\text { por frutos }\end{array}$ & $\begin{array}{c}\text { Massa de } \\
100 \text { grãos }(\mathrm{g})\end{array}$ & $\begin{array}{c}\text { Produtividade } \\
\text { de grãos } \\
\left(\mathrm{kg} \mathrm{h}^{-1}\right)\end{array}$ \\
\hline $\begin{array}{l}\text { Planta de cobertura } \\
\text { Crotalária }\end{array}$ & $30.185 \mathrm{~b}$ & $2,35 \mathrm{a}$ & $24,9 \mathrm{~b}$ & $2,9 \mathrm{a}$ & $39,4 \mathrm{~b}$ & $2.003 \mathrm{c}$ \\
Milheto & $37.593 \mathrm{a}$ & $1,86 \mathrm{c}$ & $27,0 \mathrm{~b}$ & $3,0 \mathrm{a}$ & $40,2 \mathrm{ab}$ & $2.129 \mathrm{~b}$ \\
Crotalária+Milheto & $36.667 \mathrm{a}$ & $2,10 \mathrm{~b}$ & $30,0 \mathrm{a}$ & $3,0 \mathrm{a}$ & $41,5 \mathrm{a}$ & $2.878 \mathrm{a}$ \\
CV(\%) & 16,8 & 5,7 & 7,8 & 4,1 & 3,8 & 4,0 \\
Manejo mecânico & & & & & 4,0 \\
Sem & $37.531 \mathrm{a}$ & $2,07 \mathrm{a}$ & $27,1 \mathrm{a}$ & $3,0 \mathrm{a}$ & $4,8 \mathrm{a}$ & $2.545 \mathrm{a}$ \\
Com & $32.098 \mathrm{~b}$ & $2,13 \mathrm{a}$ & $27,5 \mathrm{a}$ & $2,9 \mathrm{a}$ & $39,0 \mathrm{~b}$ & $2.129 \mathrm{~b}$ \\
CV $(\%)$ & 9,6 & 4,0 & 5,3 & 4,9 & 6,4 & 7,7 \\
\hline
\end{tabular}

Médias seguidas por letras iguais, na coluna, dentro de cada fator, não diferem entre si pelo teste t (DMS), a 5\% de probabilidade. 
devido às menores variações na temperatura e no teor de água do solo, proporcionadas pela maior cobertura vegetal do milheto e do consórcio ou pela ausência de manejo mecânico (Tabela 1).

O número de racemos por planta foi maior quando a mamona foi cultivada em sucessão à crotalária (Tabela 2). É provável que a menor população de plantas no tratamento com crotalária proporcionou o menor número de racemos por planta. Maiores populações de plantas proporcionam menor número de racemos por planta (SOUZA-SCHLICK, 2010). Contudo, o manejo mecânico da palhada não interferiu no número de racemos por planta.

Em relação ao número de frutos por racemo e à massa de 100 grãos, constatou-se que o consórcio crotalária + milheto proporcionou os maiores valores, especialmente quando comparado à crotalária (Tabela 2). O milheto, por ser uma planta com alta capacidade de reciclar nutrientes do solo, principalmente $\mathrm{K}$, e a crotalária, altamente eficiente em fixar o $\mathrm{N}$ atmosférico, proporcionaram suprimento mais equilibrado de nutrientes em relação aos demais tratamentos. O K possui papel importante na formação dos frutos, atuando no transporte de fotoassimilados no floema. A deposição de biomassa no fruto é acompanhada, necessariamente, pelo acúmulo de K (MARSCHNER, 1995). Já a ausência do N impede o crescimento inicial da planta (MALAVOLTA et al., 1997), e a frutificação, quando ocorre, é fraca com poucos racemos e frutos com massa abaixo do esperado. Quanto ao manejo das plantas de cobertura, a ausência de manejo mecânico proporcionou massa de 100 grãos superior ao tratamento com manejo mecânico. É possível que a trituração da palha possa ter acelerado a taxa de liberação dos nutrientes, diminuindo a disponibilidade destes durante a fase final de florescimento e enchimento de grãos (ARGENTA et al., 2001), bem como diminuído a proteção da palha ao solo.

O número de grãos por fruto não foi afetado pelos fatores estudados (Tabela 2). O consórcio crotalária + milheto proporcionou maior produtividade de grãos $\left(2.878 \mathrm{~kg} \mathrm{ha}^{-1}\right)$, seguido do milheto $(2.129 \mathrm{~kg}$ $\mathrm{ha}^{-1}$ ), sendo ambos os valores maiores que o proporcionado pela crotalária $\left(2.003 \mathrm{~kg} \mathrm{ha}^{-1}\right)$ (Tabela 2$)$. O melhor desempenho da mamona em sucessão ao consorcio crotalária + milheto se deve ao fato de este ter proporcionado valores superiores de frutos por racemo e massa de 100 grãos que o tratamento sobre palhada de milheto. PERIN et al. (2006) verificaram que, na ausência de $\mathrm{N}$-fertilizante, o cultivo prévio do consórcio crotalária+milheto resultou em maior produtividade do milho que a crotalária ou o milheto solteiros. Esse efeito foi atribuído à liberação de $\mathrm{N}$ mais sincronizada com o requerimento do milho. Apesar de ter proporcionado melhor estabelecimento da cultura, provavelmente devido à maior cobertura do solo (Tabelas 1 e 2), o cultivo anterior do milheto solteiro provavelmente proporcionou menor disponibilidade de $\mathrm{N}$ para a mamoneira, resultando em menor número de racemos por planta e produtividade de grãos. PERIN et al. (2006) verificaram menor acúmulo de $\mathrm{N}$ no milho cultivado em sucessão ao milheto do que à crotalária solteira e ao consórcio milheto + crotalária.

A ausência de manejo mecânico das plantas de cobertura proporcionou maior produtividade de grãos da mamona (Tabela 2), evidenciando que a operação de manejo da palhada não se faz necessária para o cultivo da mamona em sucessão ao milheto, à crotalária ou ao consórcio milheto + crotalária. Tal resultado é reflexo do observado para a população de plantas e a massa de cem grãos. O uso de implementos específicos ao manejo da palhada de plantas de cobertura pode acarretar desvantagens, tais como: alto custo, baixo rendimento operacional e riscos de compactação do solo (DENARDIN \& KOCHHANN, 1993). Além disso, o esfacelamento torna os resíduos mais suscetíveis ao processo de decomposição.

\section{CONCLUSÃO}

O milheto produz maior quantidade de MS e contém maiores teores de $\mathrm{K}, \mathrm{Mg}$ e $\mathrm{S}$ na parte aérea, aos 75DAE, enquanto a crotalária contém maiores teores de $\mathrm{Ne} \mathrm{Ca}$. O milheto acumula mais $\mathrm{N}, \mathrm{P}, \mathrm{K}, \mathrm{Mg}$ e $\mathrm{S}$ na parte aérea, enquanto a crotalária acumula mais $\mathrm{Ca}$. A produtividade de grãos da mamoneira é maior em sucessão ao consórcio crotalária + milheto e na ausência do manejo mecânico da palhada.

\section{AGRADECIMENTOS}

\begin{abstract}
À Fundação de Amparo à pesquisa do Estado de São Paulo (Fapesp), pelo financiamento do projeto e pela concessão de bolsa de Iniciação Científica ao primeiro autor, e ao Conselho Nacioanal de Pesquisa (CNPq), pela concessão de bolsas de Produtividade em Pesquisa ao segundo e terceiro autores.
\end{abstract}

\section{REFERÊNCIAS}

ALVARENGA, R.C. et al. Plantas de coberturas de solo para sistema plantio direto. Informe agropecuário, Belo Horizonte, v.22, n.208, p.25-36, 2001.

ARGENTA, G. et al. Efeitos do manejo mecânico e químico da aveia-preta no milho em sucessão e no controle do capimpapuã. Pesquisa Agropecuária Brasileira, Brasília, v.36, n.6, p.851-860, 2001. Disponível em: <http://www.scielo.br/ pdf/pab/v36n6/a02v36n6.pdf>. Acesso em: 18 jan. 2010. doi: 10.1590/S0100-204X2001000600002. 
BOER, C.A. et al. Ciclagem de nutrientes por plantas de cobertura na entressafra em um solo de cerrado. Pesquisa Agropecuária Brasileira, Brasília, v.42, p.1269-1276, 2007. Disponível em: 〈http://www.scielo.br/pdf/pab/v42n9/08.pdf>. Acesso em: 20 jan. 2010. doi: 10.1590/S0100-204X2007000900008.

CARPIM L.K. et al. Liberação de nutrientes pela palhada de milheto em diferentes estádios fenológicos. Revista Brasileira de Ciência do Solo, Viçosa, v.32, n.especial, p.2813-2819, 2008. Disponível em: <http://www.scielo.br/pdf/rbcs/v32nspe/ 27.pdf>. Acesso em: 15 jan. 2010. doi: 10.1590/S010006832008000700027.

CAZETTA, D.A. et al. Composição, produção de MS e cobertura do solo em cultivo exclusivo e consorciado de milheto e crotalária. Acta Scientiarum. Agronomy, Maringá, v.27, n.4, p.575-580, 2005. Disponível em: <http://periodicos.uem.br/ ojs/index.php/ActaSciAgron/article/view/1298/1090>. Acesso em: 20 jan. 2010. doi: 10.4025/actasciagron.v27i4.1298.

CRUSCIOL, C.A.C.; SORATTO, R.P. Nitrogen supply for cover crops and effects on peanut grown in succession under a no-till system. Agronomy Journal, Madison, v.101, n.1, p.41-46, 2009. Disponível em: <https://www.agronomy.org/publications/ aj/articles/101/1/41>. Acesso em: 16 jan. 2010. doi: 10.2134/ agronj2008.0054.

CRUSCIOL, C.A.C.; SORATTO, R.P. Nutrição e produtividade do amendoim em sucessão ao cultivo de plantas de cobertura no sistema plantio direto. Pesquisa Agropecuária Brasileira, Brasília, v.42, n.11, p.1553-1560, 2007. Disponível em: < http://www.scielo.br/pdf/pab/v42n11/v42n11a06.pdf>. Acesso em: 16 jan. 2010. doi: 10.1590/S0100-204X2007001100006.

DAROLT, M. R. Princípios para implantação e manutenção do sistema. In: DAROLT, M. R. Plantio direto: pequena propriedade sustentável. Londrina: Iapar, 1998. p.16-45. (Circular, 101).

DENARDIN, J.E.; KOCHHANN, R.A. Requisitos para implantação e a manutenção do sistema plantio direto. In: EMBRAPA. Centro Nacional de Pesquisa de Trigo (Passo Fundo, RS). Plantio Direto no Brasil. Passo Fundo: Aldeia Norte. EMBRAPA-CNPT; FECOTRIGO-FUNDACEP e FUNDAÇÃO ABC. 1993. p.19-27.

FERREIRA, D.F. Manual do sistema Sisvar para análises estatísticas. Lavras: UFLA, 2000. 66p.

MALAVOLTA, E. et al. Avaliação do estado nutricional das plantas: princípios e aplicações. 2.ed. Piracicaba : Potafós, 1997. 319p.

MARSCHNER, H. Mineral nutrition of higher plants. 2.ed. London: Academic, 1995. 889p.

MENDONÇA, E.H.M.M.; SCHIAVINATO, M.A. Growth of Crotalaria juncea $\mathrm{L}$. supplied with mineral nitrogen. Brazilian Archives of Biology and Technology, Curitiba, v.48, n.2, p.181-185, 2005. Disponível em: <http://www.scielo.br/pdf/ babt/v48n2/23756.pdf $>$. Acesso em: 16 jan. 2010. doi: 10.1590/S1516-89132005000200003.

MENEZES, L.A.S. et al. Produção de fitomassa de diferentes espécies, isoladas e consorciadas, com potencial de utilização para cobertura do solo. Bioscience Journal, Uberlândia, v.25, n.1, p.7-12, 2009. Disponível em: <http://www.seer.ufu.br/ index.php/biosciencejournal/article/viewFile/6657/4384>. Acesso em: 16 jan. 2010.

NASCIMENTO, M.S. Marcha de absorção de nutrientes em dois híbridos de mamona de porte baixo. 2009. $100 \mathrm{f}$. Tese (Doutorado em Agronomia/Agricultura) - Universidade Estadual Paulista, Faculdade de Ciências Agronômicas, Botucatu,SP.

NASCIMENTO, J.T.; SILVA, I.P. Avaliação quantitativa e qualitativa da fitomassa de leguminosas para uso como cobertura de solo. Ciência Rural, Santa Maria, v.34, n.3, p.947-949, 2004. Disponível em: <http://www.scielo.br/pdf/cr/v34n3/ a47v34n3.pdf>. Acesso em: 16 jan. 2010. doi: 10.1590/S010384782004000300047

NASS, L.L. et al. Biofuels in Brazil: an overview. Crop Science, Madison, v.47, n.6, p.2228-2237, 2007. Disponível em: <https:/ /www.soils.org/publications/cs/articles/47/6/2228>. Acesso em: 16 jan. 2010. doi: 10.2135/cropsci2007.03.0166.

OLIVEIRA, T.K. et al. Plantas de cobertura e seus efeitos sobre o feijoeiro em plantio direto. Pesquisa Agropecuária Brasileira, Brasília, v.37, n.8, p.1079-1087, 2002. Disponível em: <http://www.scielo.br/pdf/pab/v37n8/11667.pdf>. Acesso em: 8 jan. 2010. doi: 10.1590/S0100-204X2002000800005.

PERIN, A. et al. Sunnhemp and millet as green manure for tropical maize production. Scientia Agricola, Piracicaba, v.63, n.5, p.453-459, 2006. Disponível em: <http://www.scielo.br/ pdf/sa/v63n5/31405.pdf>. Acesso em: 8 jan. 2010. doi: 10.1590/ S0103-90162006000500006.

PERIN, A. et al. Produção de fitomassa, acúmulo de nutrientes e fixação biológica de nitrogênio por adubos verdes em cultivo isolado e consorciado. Pesquisa Agropecuária Brasileira, Brasília, v.39, n.1, p.35-40, 2004. Disponível em: <http:// www.scielo.br/pdf/pab/v39n1/19581.pdf $>$. Acesso em: 8 jan. 2010. doi: 10.1590/S0100-204X2004000100005.

ROSOLEM, C.A. et al. Nitrogen management in maize cover crop rotations. Plant and Soil, Dordrecht, v.264, n.1-2, p. 261-271, 2004. Disponível em: <http://www.springerlink.com/ content/q12g21j837q88770/fulltext.pdf>. Acesso em: 8 jan. 2010. doi: 10.1023/B:PLSO.0000047761.50641.a3.

SANTOS, R.F. et al. Aspectos econômicos do agronegócio da mamona. In: AZEVEDO, D.M.P.; BELTRÃO, N.E.M. O agronegócio da mamona no Brasil. 2.ed. Campina Grande: Embrapa Algodão; Brasília : Embrapa Informação Tecnológica, 2007. p.21-41.

SOUZA, E.D. et al. Fitomassa e acúmulo de nitrogênio, em espécies vegetais de cobertura do solo para um Latossolo Vermelho distroférrico de Cerrado. Acta Scientiarum. Agronomy, Maringá, v.30, n.4. p.525-531, 2008. Disponível em: <http://periodicos.uem.br/ojs/index.php/ActaSciAgron/ article/view/5313/5313>. Acesso em: 8 jan. 2010. doi: 10.4025/ actasciagron.v30i4.5313.

SOUZA-SCHLICK, G.D. Espaçamento entre fileiras e população de plantas para cultivares de mamona de porte baixo na safra de verão e safrinha. 2010. 108f. Dissertação 
(Mestrado em Agronomia/Agricultura) - Universidade Estadual Paulista, Faculdade de Ciências Agronômicas, Botucatu, SP.

TEDESCO, M.J. et al. Análises de solo, plantas e outros materiais. Porto Alegre: Universidade Federal do Rio Grande do Sul, 1985. 188p. (Boletim técnico, 5).
ZUCHI, J. et al. Características agronômicas de cultivares de mamona em função do local de cultivo e da época de semeadura no Rio Grande do Sul. Ciência Rural, Santa Maria, v.40, n.3, p.501-506, 2010. Disponível em: <http://www.scielo.br/pdf/ cr/v40n3/a508cr1975.pdf >. Acesso em: 8 jan. 2010. doi: 10.1590/S0103-84782010000300001. 